\title{
A LARGE SCALE HYBRID THERMAL PRINT HEAD
}

\author{
TAMIO SAITO, YOSHIKATSU FUKUMOTO, MAMORU MIZUGUCHI, \\ TAKAHIKO ABE and MASAYOSHI NAGASHIMA \\ Toshiba Corporation, Suehirocho 2-9, Ome City, Tokyo, Japan 198
}

(Received June 5, 1981; in final form June 26, 1982)

\begin{abstract}
A high speed direct drive thermal print head, which prints across a $216 \mathrm{~mm}$ wide paper using 1728 heating resistor dots $(8 \mathrm{dots} / \mathrm{mm})$ has been developed.

It can print $30 \mathrm{~cm}$ long paper in only a few seconds. The head consists of heating dots, over three hundred LSI chips, a couple of dozen capacitors and multilayer thin and thick film circuit substrate.

The substrate is $240 \times 70 \mathrm{~mm}$ by $1.0 \mathrm{~mm}$ thick conductor line width/space is $50 \mu / 50 \mu$. Hybridizing heating elements, drivers and shift registers on one substrate has made it possible to transmit signals serially into the head.

Therefore, the I/O pin number has become far smaller than the number of dots, which has eliminated intermittent $\mathrm{I} / \mathrm{O}$ pin disconnection.
\end{abstract}

\section{INTRODUCTION}

The thermal print head heats small areas on the thermal sensitive paper in the form of multiple dots arranged to obtain a required pattern. The conventional head merely consists of heating elements array. A little more advanced thermal head consists of heating dots and conductor matrix combined with diode isolation.

In these cases, drivers or shift registers to drive the elements are mounted on the printed circuit board, where they are electrically connected to a thermal print head, usually with a flat cable.

Intermittent disconnections in the multiple conductor flatcable contacts often occur. The developed thermal print head is a one-piece thermal print hybrid module, consisting of heating dots, shift register LSIs, driver IC chips and multilayer circuit. Thus, as mentioned in the abstract, intermittent disconnection has been eliminated.

In order to manufacture the one-piece module, a hybrid process of thick film screen printing, photolitographic thick film firable evaporated thin film non firable evaporated thin film, sputtered cermet or oxide film, plating, chip die mounting, wire bonding and repairable hermetic sealing has been developed.

Developed one-piece thermal print head size is $1 / 20$ the conventional unit size.

\section{DESIGN}

The $99.5 \%$ alumina substrate is $240 \times 70 \times 10 \mathrm{t}(\mathrm{mm}) .1728$ heating resistor dots are formed on the glaze mesa. The dot is $100 \mu \times 200 \mu$ and the dot to dot pitch is $125 \mu$, thus the space is $25 \mu$.

All dots are electrically connected to the hammer driver, whose inputs are connected to 32 bit latchable bilateral shift registers throughout the substrate.

There are over 300 semiconductor chips and almost 30 noise killing capacitors. The shift register shift clock is $1 \mathrm{MHz}$. Each 512 bit shift register has shift register signal input, thus shifting time is $512 \mu \mathrm{sec}$. At the end of shifting, all data can be latched and 
the output from the register is the latched data, independent of shift register data and movement.

All the 1728 dots can be driven simultaneously, if necessary, Heating dots driving time is 0.6 to $3.0 \mathrm{msec}$ and maximum duy is $50 \%$. Thus, the minimum printing time required for an A4 sheet of paper is 2.8 seconds.

The peak driving power of each dot is 0.5 to $1.4 \mathrm{~W}$, being inversely proportional to driving time.

A block diagram of the head is shown in Figure 1.

\section{CONFIGURATION}

A drawing of the developed module is shown in Figure 2.

1728 dots are lined in parallel with a common electrode to which all heating dots are connected.

Conductor lines, coming from the other side of the dots, go under the dielectric layer. Underneath the heating dots, a glaze mesa is formed to get $\mathrm{m}$-second order heating insulation.

A cross-sectional view is shown in Figure 3.

LSI chips are mounted and wire bonded to the substrate and hermetically sealed by a metal cap with solder.

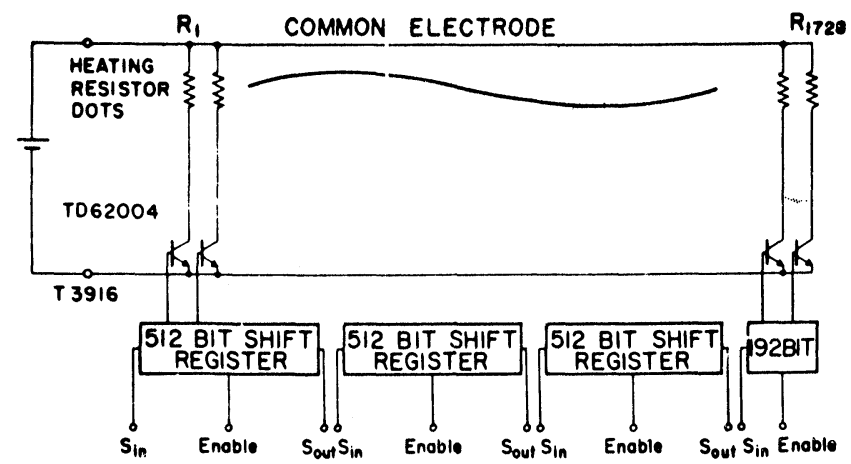

FIGURE 11728 dot direct drive thermal print head equivalent circuit.

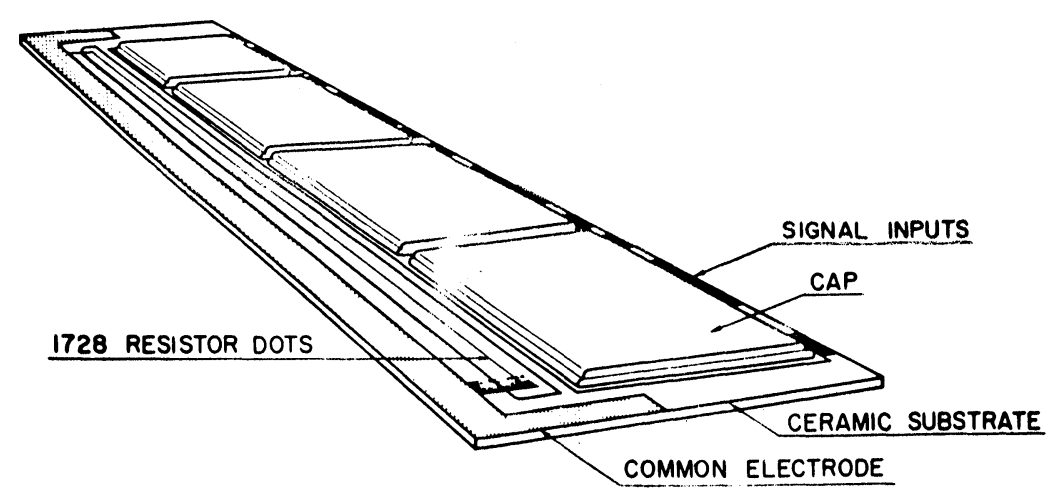

FIGURE 2 A4-8dot direct drive module. 
Inert gas is charged into the cap. As the cap is soldered, it can be easily removed, and new chips can be mounted to replace a damaged one.

In order to protect fine lines near resistors, a cover glaze is sputtered over the resistors and lines.

This material is hard enough to endure traversing $100 \mathrm{~km}$ over the print paper. Due to the hermetic sealing and this sputtered glaze protection, all circuits are completely protected from moisture.

\section{MANUFACTURING PROCESS}

This module can be called not only a hybrid of many elements, but also a hybrid manufacturing process. This process is shown in Table 1.

Primarily, gold or silver paste is printed on the ceramic substrate with screen printing technology.

1 st metal is formed by metal evaporation and photo etching process. A photograph is shown in Figure 4. The detail of this material and manufacturing process was previously reported by the author. ${ }^{1}$ It is firable and repairable with gold conductor paste.

Thus, even first metal dimensions are as small as $50 \mu$ space and its yield is almost $100 \%$.

1st dielectric layer is processed by thickfilm printing and photo lithographic patterning, whose details were also reported in a previous paper.

2nd dielectric process is the same as the 1 st dielectric process. The via filling process has also been previously reported. . $^{1}$

Sealing dielectric, seal ring, common electrode and glaze are screen printed. After the circuit process completion, the substrate will be submitted to short-open test. If a fault is found, the circuits can be repaired by thick film paste.

TABLE I

A4-8DD manufacturing process.

\begin{tabular}{|c|c|c|c|}
\hline Process & Material & Method & Reference \\
\hline $\begin{array}{l}\text { 1/O Leads } \\
\text { 1st metallization }\end{array}$ & $\begin{array}{l}\mathrm{Au} \text { or } \mathrm{Ag} \\
\text { Thin film Au Alloy }\end{array}$ & $\begin{array}{l}\text { Thick film printing } \\
\text { Evaporation }\end{array}$ & \\
\hline 1st Dielectric & Glass & Thick film/dry film & \\
\hline 2nd Metallization & Thin film Au alloy & Evaporation & \\
\hline 2nd Dielectric & Glass & Thick film/dry film & \\
\hline Via fill & $\mathrm{Au}$ & Mask Blade method & \\
\hline Seal ring dielectric & Glass & Thick film printing & \\
\hline Seal ring & $\mathrm{Au}$ & Thick film printing & \\
\hline Common electrode & $\mathrm{Au}$ or $\mathrm{Ag}$ & Thick film printing & \\
\hline Glaze & Glass & Thick film printing & \\
\hline Resistors & Tantalium Cermet & Sputtering & \\
\hline 3rd Metallization & $\mathrm{Cr}-\mathrm{Pd}-\mathrm{Au}-\mathrm{Cr}$ & Evaporation & \\
\hline Passivation & $\mathrm{Ta}_{2} \mathrm{O}_{5}$ & Sputtering & \\
\hline 4th Metallization & Ti-Au & Evaporation & \\
\hline Copper plating & $\mathrm{Cu}$ & Electro plating & \\
\hline Solder reflow & $\mathrm{Sn}^{63} \mathrm{~Pb}^{37}$ & Hot plate & \\
\hline Chip die mount & Epoxy & Auto dispenser & \\
\hline Wire bonding & $\mathrm{Au}$ & Auto bonder & \\
\hline \multicolumn{4}{|l|}{ Test } \\
\hline Hermetic seal & Inert gas & Soldering & \\
\hline
\end{tabular}




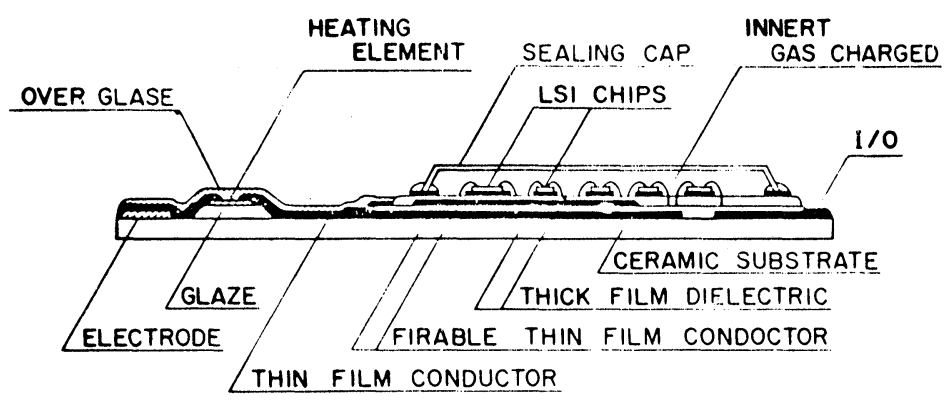

FIGURE 3 Water-proof Toshiba direct drive thermal print head cross-sectional view

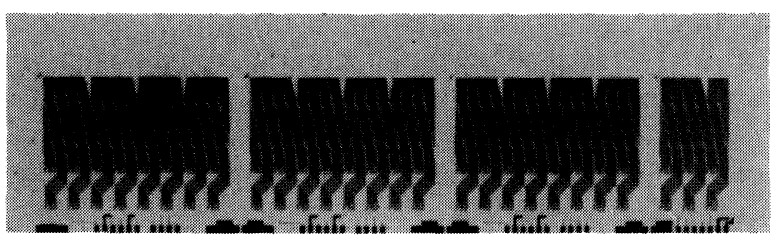

FIGURE 4 Metal forming by evaporation and photo etching process.

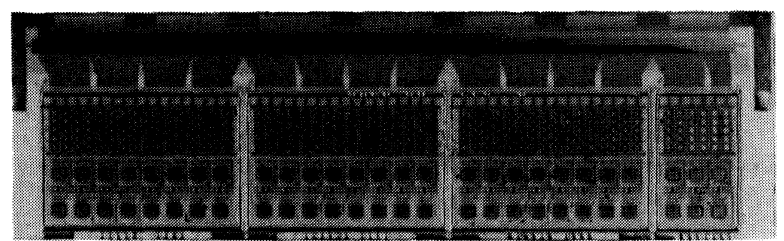

FIGURE 5 Chip mounted and wire bonded sample.

Resistor material $\mathrm{Ta}-\mathrm{SiO}_{2}$ is sputtered and gold film is successively evaporated with adhesive metal. After the photolithographic patterning of gold conductor and resistor, $\mathrm{Ta}_{2} \mathrm{O}_{5}$ is sputtered over it.

Then, gold conductor paste pattern, which is to be soldered, will be copper plated to get good solder leach resistance. Solder is reflowed over the copper pattern.

There are close to 6000 bonding wires. By multichip automatic wire bonder, bonding can be completed in less than one hour.

The chip mounted and wire bonded sample is shown in Figure 5.

After printing tests, the hybrid will be hermetically capped.

Characters printed by this head are shown in Figure 6. A prototype thermal printer model is shown in Figure 7.

A size comparison between the developed thermal print head and a conventional unit is shown in Figure 8.

This particular example is for use in railroad ticket vending machines. ${ }^{2,3}$

A conventional unit consists of Dips on PCB, flexible cable and a printing head (Figure 8 , top). The developed unit is one piece (Figure 8. bottom). The interior of the new head (Figure 8, bottom) is shown in Figure 9. 


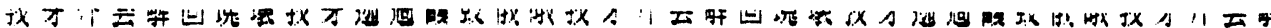

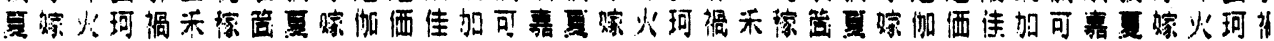

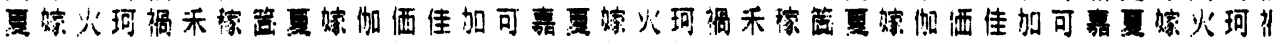

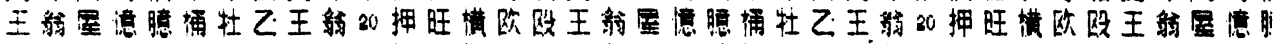

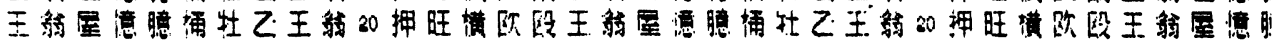

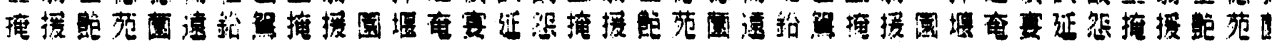

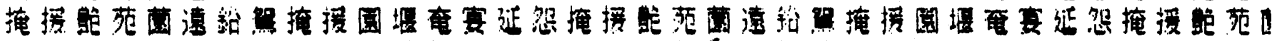

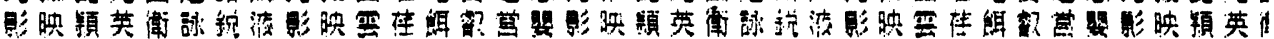

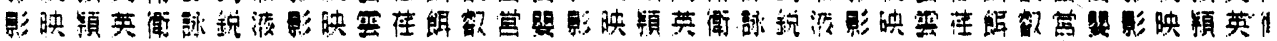

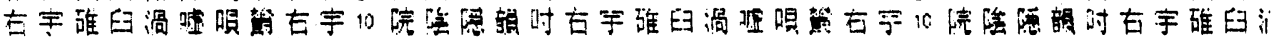

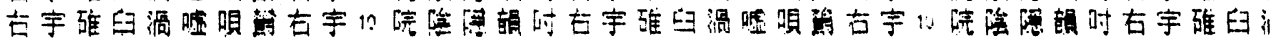

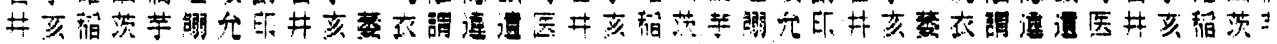

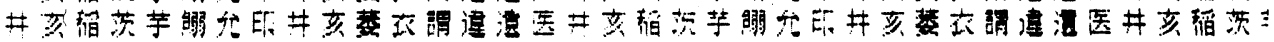

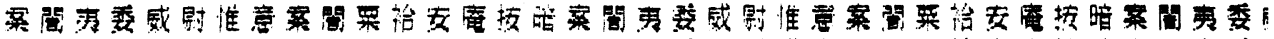

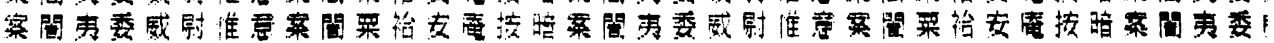

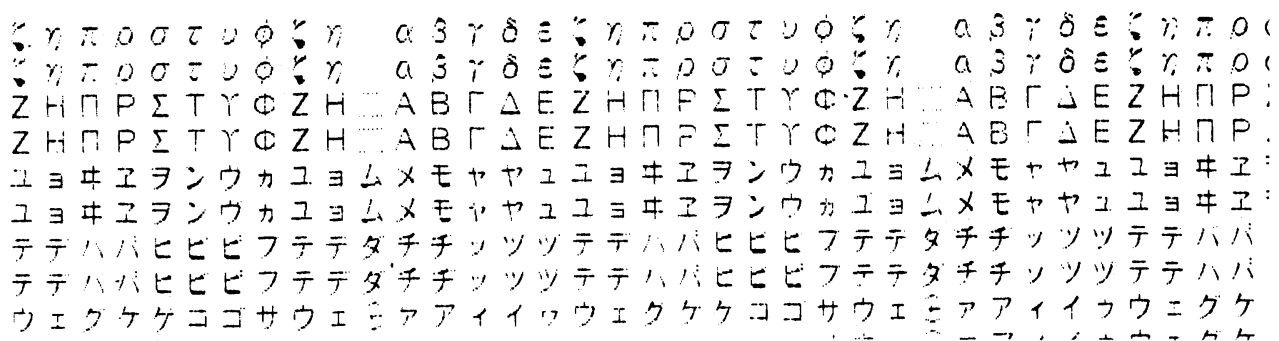

FIGURE 6 Characters printed by Thermal Print Head.

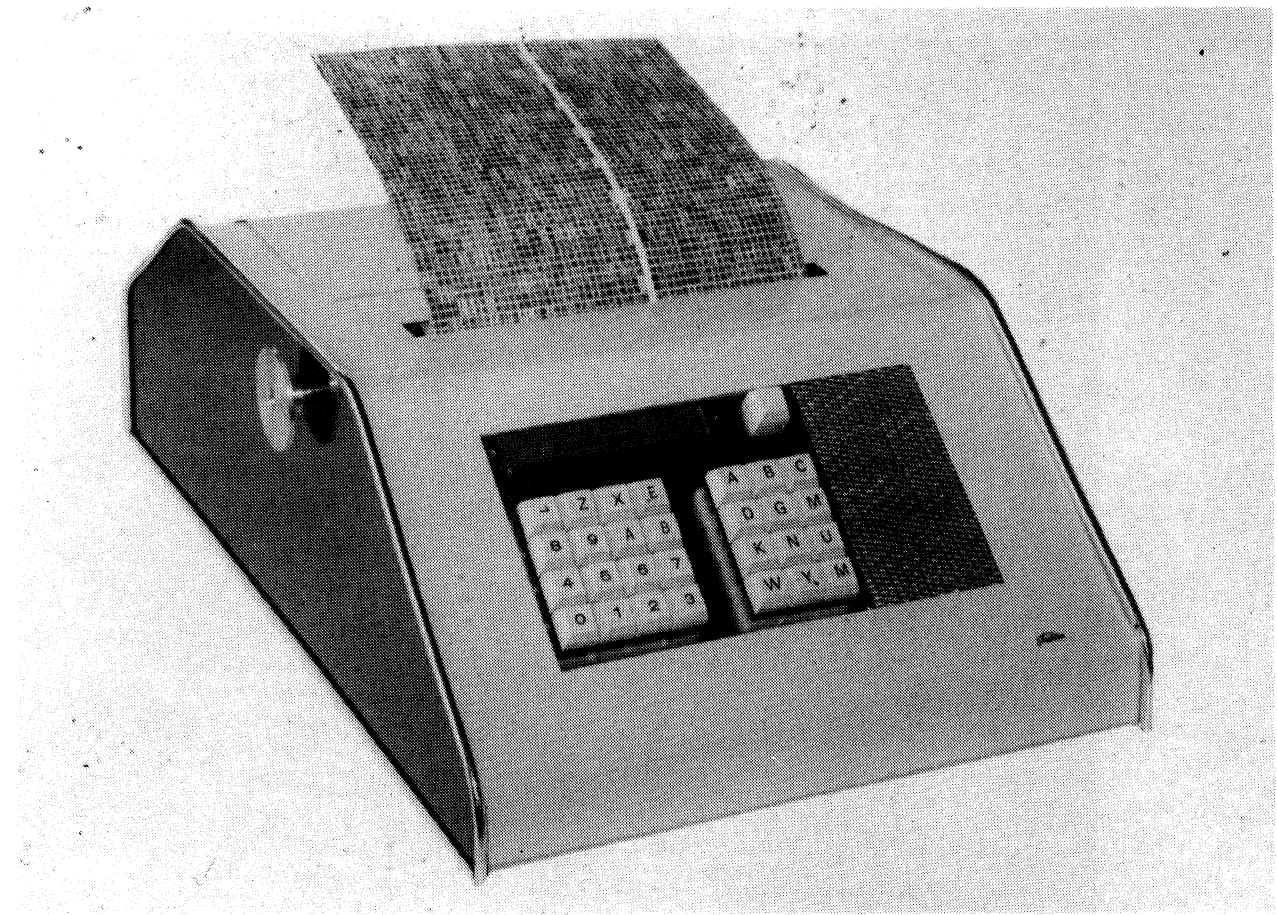

FIGURE 7 Model of Thermal Print Head. 


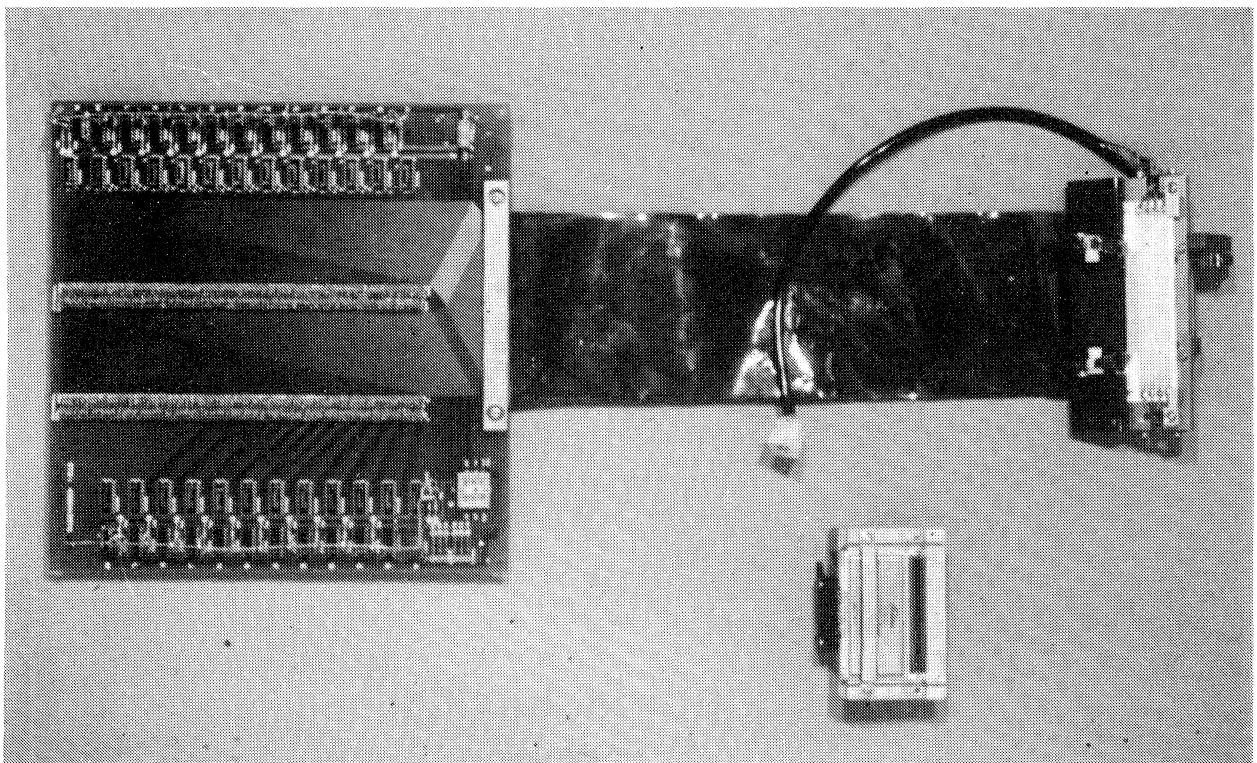

FIGURE 8 Size comparison between a conventional unit (top) and the new Thermal Print Head (bottom).

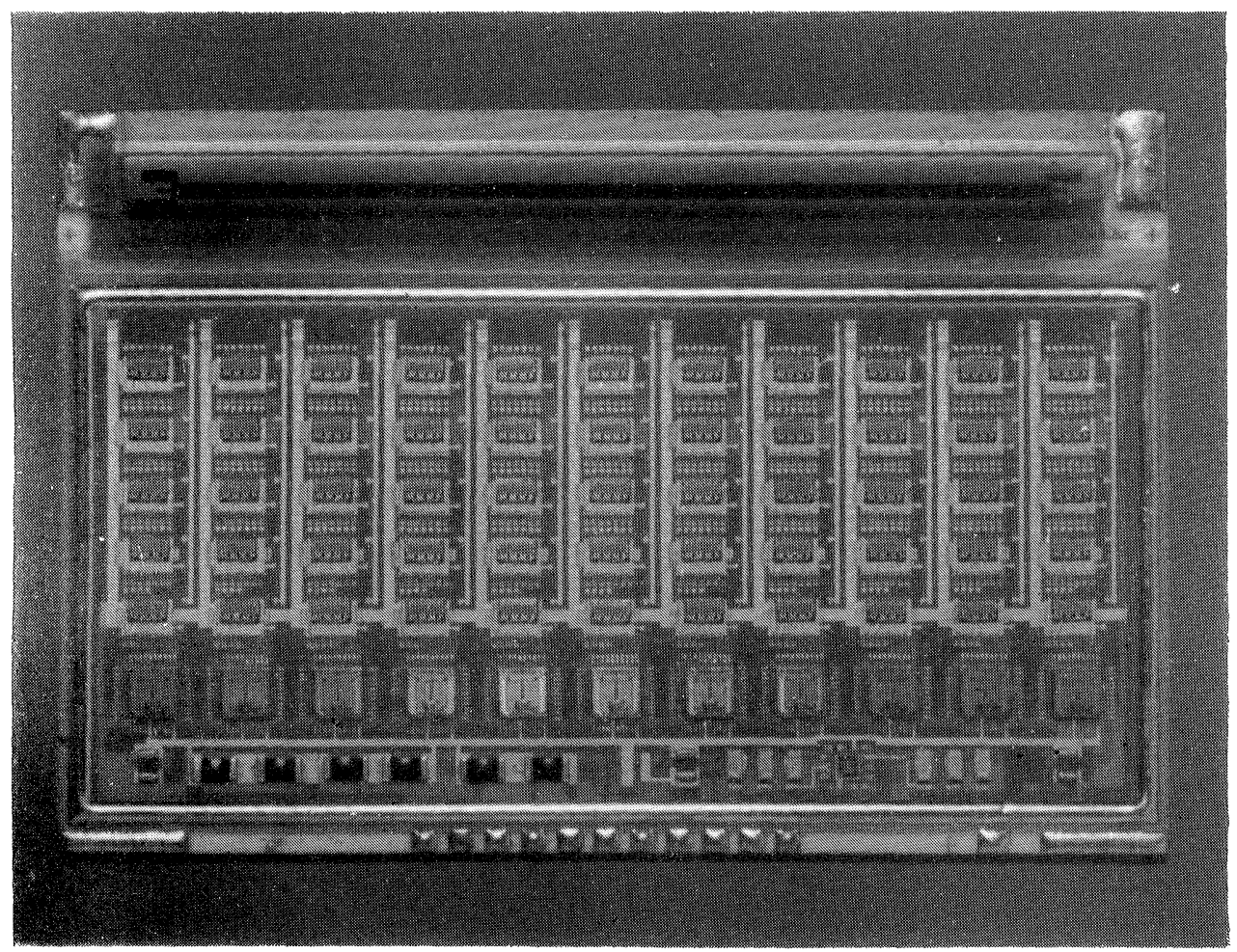

FIGURE 9 The interior of the new Thermal Print Head. 


\section{CONCLUSION}

One piece hybridization of resistors, drivers and shift resistors with hybrid technology for evaporation, sputtering, firable thin film, thick film photolithographic thick film, automatic wire bonding and hermetic sealing, has made it possible to reduce thermal print head size to $1 / 20$ th the conventional unit size, to eliminate intermitted disconnection error in multiple connections and to provide easy handling during the maintenance.

\section{ACKNOWLEDGEMENT}

The authors are grateful to Dr. Kishi and Mr. Nishi for their suggestion and encouragement, to Mr. Komine for assembly technology development, to Mr. Kamikawa, Mr. Ozeki and Mr. Oshima for art work design, to Mr. Murakami and Mr. Takeno for resistor process support, and to all members of Toshiba R \& D Center for their help in this development.

1. Tamio Saito, Yoshitaka Fukumoto and Kyomi Tagaya, "Multilayer 2 mil line technology", Proceedings International Microelectronics Conference, (May 1980).

2. Tamio Saito, Masayoshi Nagashima, Yoshikatsu Fukumoto, Yoshitaka Fukuoka, "New thermal print head for railroad ticket vending machine", Opt. 8 Fig. Conference (Japan), (Dec. 1980).

3. Charles Cohen, "2-mil lines condense multilayer hybrids," Electronics, (July 1980). 

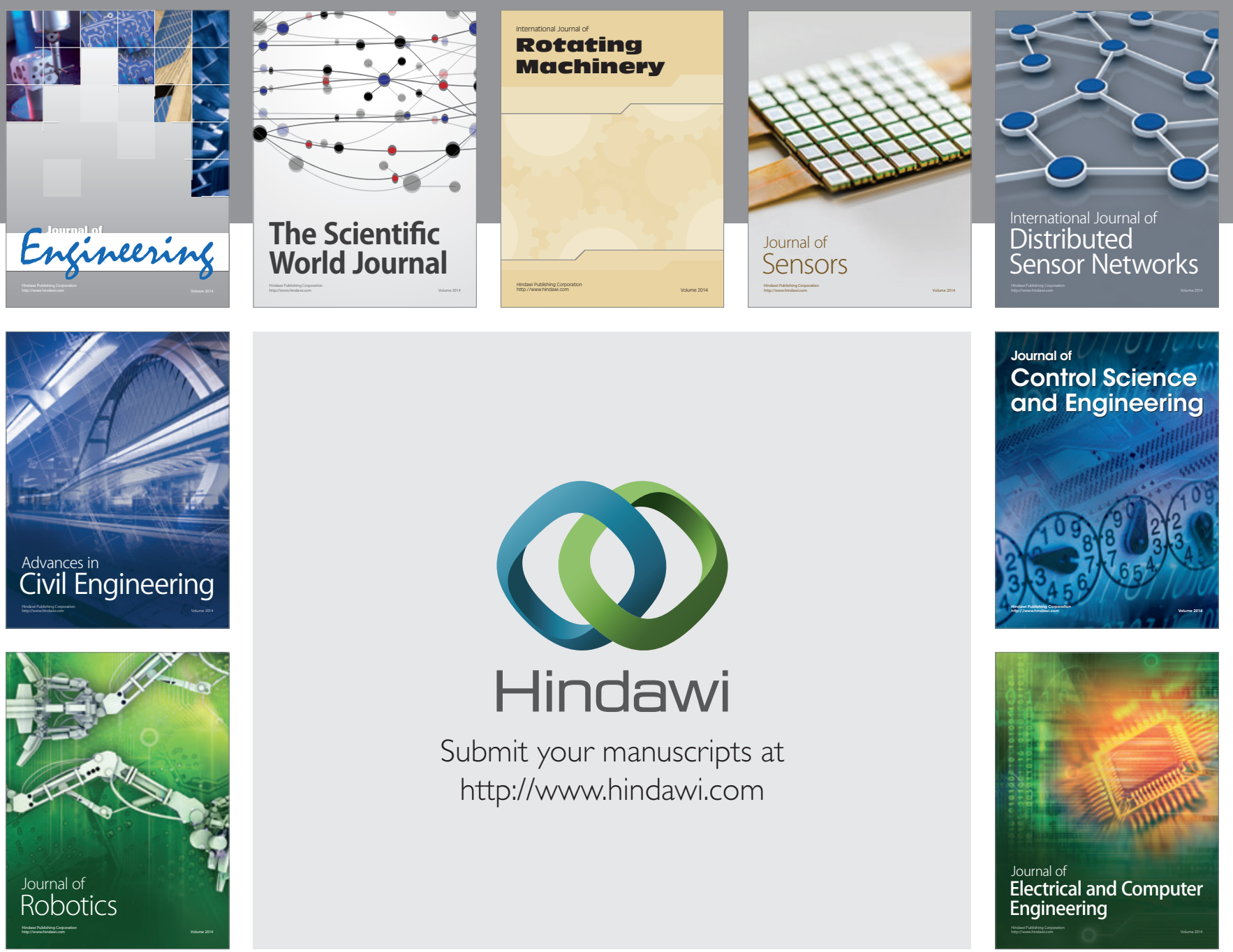

Submit your manuscripts at

http://www.hindawi.com
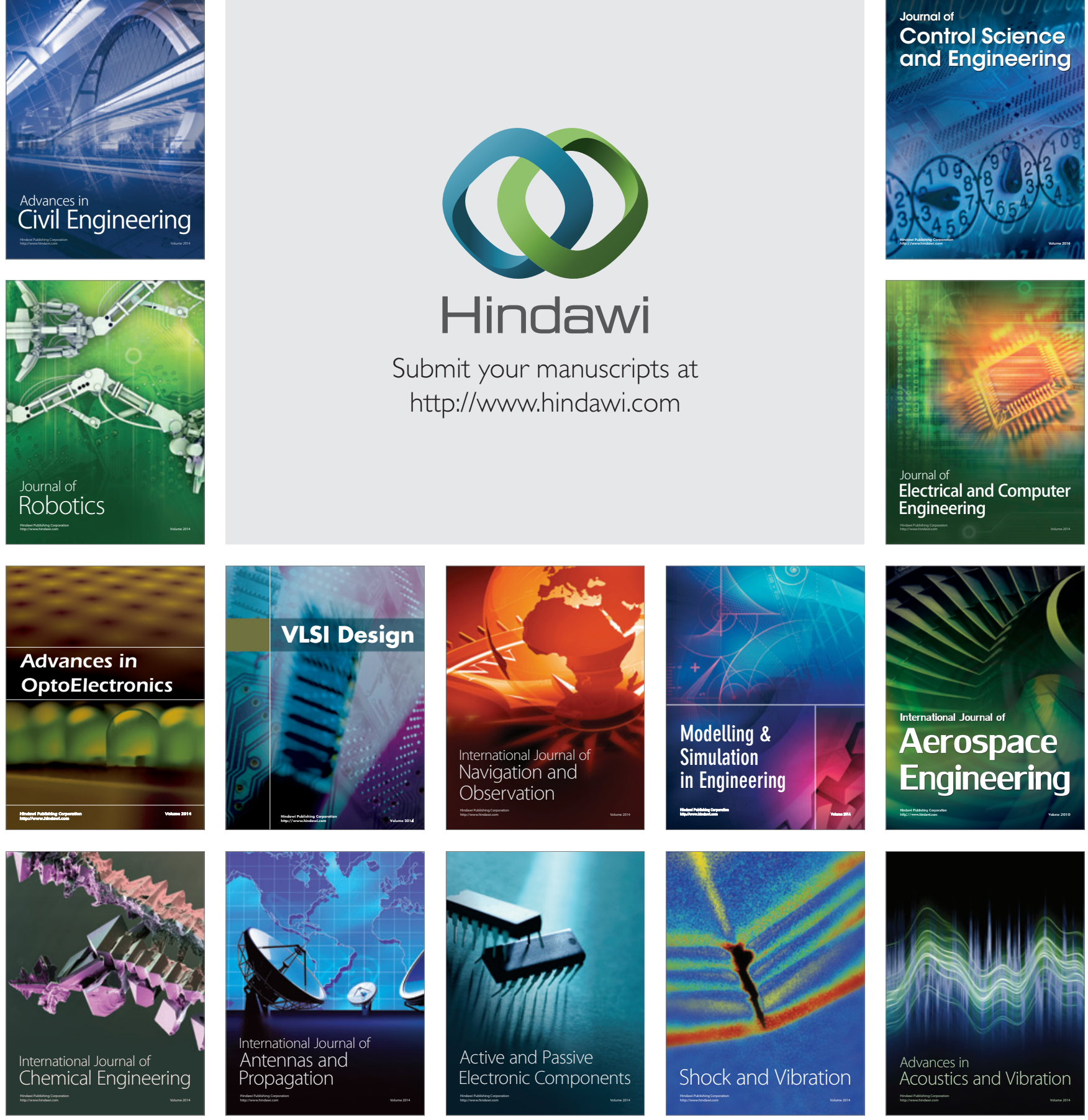